NBSIR 85-3149 (K)

\title{
Ultraclean Semiconductor Processing Laboratory Safe Operating Procedures Manual
}

G. P. Carver

U.S. DEP.ARTMENT OF COMMERCE

Nationai Bureau of Standards

National Engineering Laboratory

Center for Electronics and Electrical Engineering Semiconductor Materials and Processes Division Gaithersburg, MD 20899

May 1985

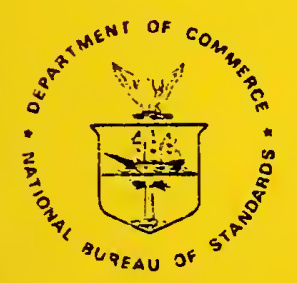

U.S. DEPARTMENT OF COMMERCE

FL BUREAU OF STANDARES

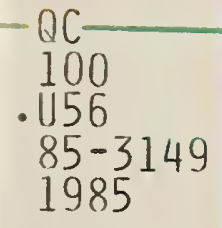



NBSIR 85-3149

ULTRACLEAN SEMICONDUCTOR

PROCESSING LABORATORY SAFE

OPERATING PROCEDURES MANUAL

G. P. Carver

U.S. DEPARTMENT OF COMMERCE

National Bureau of Standards

National Engineering Laboratory

Center for Electronics and Electrical Engineering

Semiconductor Materials and Processes Division

Gaithersburg, MD 20899

May 1985

U.S. DEPARTMENT OF COMMERCE, Malcolm 8aldrige, Secretary NATIONAL BUREAU OF STANDARDS. Emest Ambler, Diroctor 

FUREWORD AND DISCLAIMERS ................. . . v v

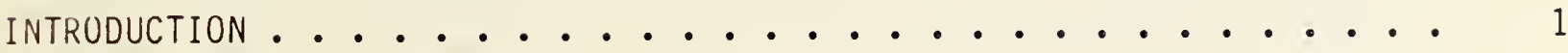

Purpose .................... 1

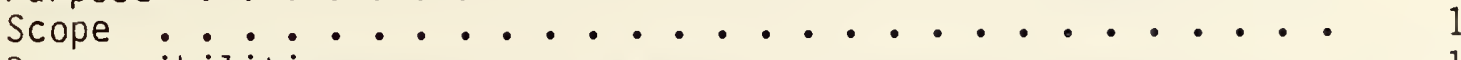

Responsibilities................ 1

Laboratory Function ............... 1

Laboratory Layout ............... 2

Emergency Notification List........... 2

GENERAL SAFETY INFORMATION ....................... 5

Major Processing Equipment........... 5

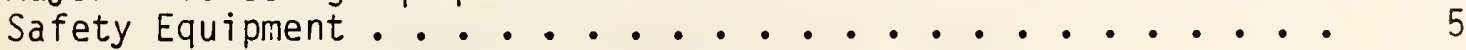

Fire Extinguishers .................. 5

Heat and Smoke Detectors............ 5

Emergency Alarms ....................... 5

Hazardous Materials Within the Laboratory ........ 5

STANDARD OPERATING PROCEDURES . . . . . . . . . . . . 14

Purpose ............................... 14

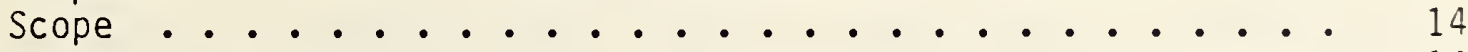

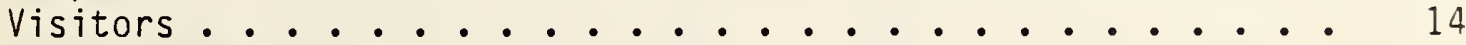

Qualified Workers ............. 15

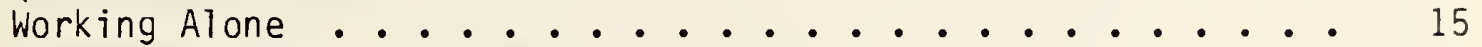

Scheduled Utility Shutdowns ............. 16

Toxic and Hazardous Compressed Gases ........... 17

Policy .......................... 17

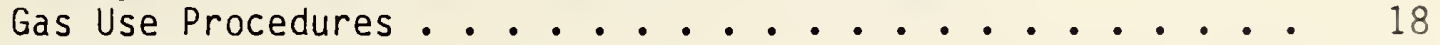

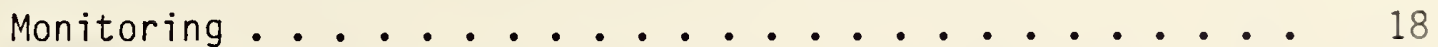

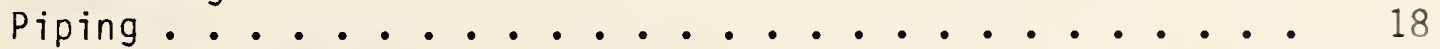

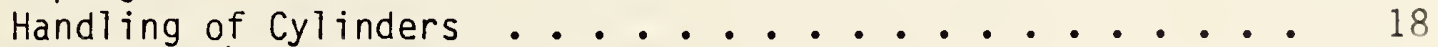

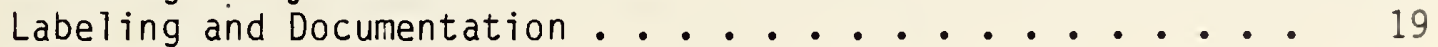

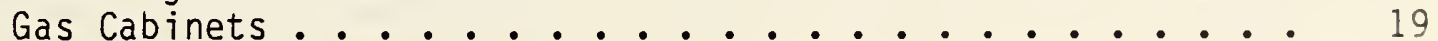

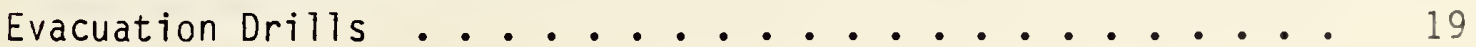

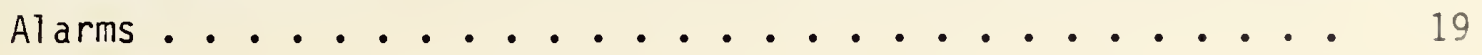

EMERGENCY OPERATING PROCEDURES . . . . . . . . . . . 20

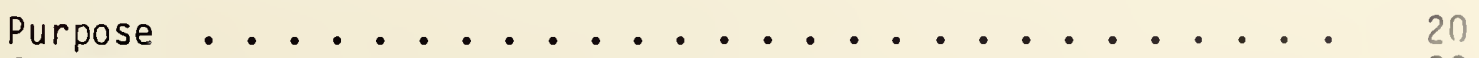

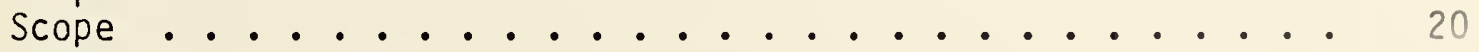

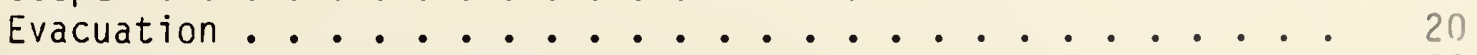

Determination to Evacuate ............ 20

Evacuation Procedures ............. 21

Use of Judgment and Evacuation Guidelines ....... 21 
Responding to Alarm Signals ............ 23

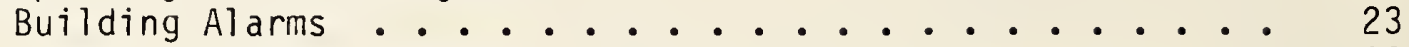

Chemical Exhaust Alarms ............... 23

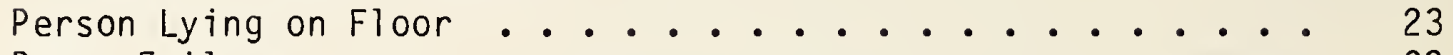

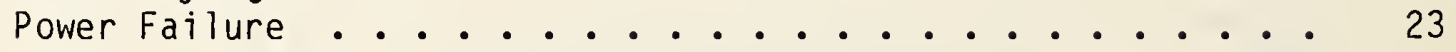

APPENDIX I: Telephone Extensions for NBS Health and Emergency

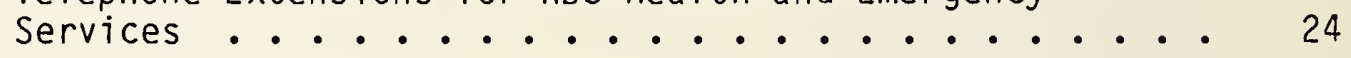

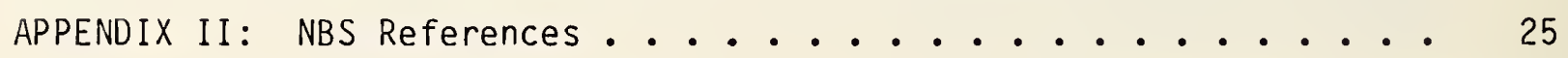

List of Tables

1. Major Processing Equipment and Associated Hazards . . . . . 6

2. Compressed Processing Gases .............. 9

3. Processing Chemicals ................... 12

\section{List of Figures}

1. USPL Schematic Layout (Major Equipment Identification) . . . .

2. USPL Schematic Layout (Safety Equipment Location) . . . . . 


\section{FOREWORD}

The standard operating procedures and emergency operating procedures in this manual are designed specifically for use in the Semiconductor Materials and Processes Division's Ultraclean Semiconductor Processing Laboratory (USPL). These procedures supplement NBS accident prevention, fire protection, facilities self-protection, and other health and safety procedures. It is assumed that all NBS-mandated procedures are followed, except where more stringent procedures in this manual are specifically intended to be substituted.

This manual covers standard operating procedures and emergency operating procedures that relate to safety, along with general information about the USPL.

Information related to NBS safety procedures is presented in two Appendices. NBS telephone extensions for health and emergency services are listed in Appendix I. Appendix II is a bibliography of NBS publications relating to safety.

A revision and update of this manual shall be made and distributed once each year and shall be the basis for one of the required safety awareness meetings of the USPL staff each year.

\section{DISCLAIMERS}

The procedures and guidelines described in this manual are intended solely for use in the NBS UItraclean Semiconductor Processing Laboratory. They relate to the specific conditions in that laboratory. There is no implication that these procedures and guidelines are applicable elsewhere. The views expressed and the conclusions developed do not necessarily represent the official policies of the National Bureau of Standards, the Department of Commerce, or the United States Government.

Certain instruments, materials, or processes may be identified to adequately define the specific conditions in the NBS UItraclean Semiconductor Processing Laboratory. Such identification does not imply recommendation or endorsement by the National Bureau of Standards, nor does it imply that the instrument, material, or process is necessarily the best available for the purpose. 



\section{INTRODUCTION}

PURPOSE :

The purpose of a Safe Operating Procedures Manual is to provide guidelines and information for the prevention of injury to personnel and damage to property.

This document outlines safety procedures, safety equipment, and other safety information concerning the Semiconductor Materials and Processes Division's Ultraclean Semiconductor Processing Laboratory (USPL). It is intended for the use of persons' who work in the USPL. It also contains information useful to NBS safety and fire protection personnel.

SCOPE :

The guidelines and procedures in this document relate to the specific and unique environmental conditions in the Ultraclean Semiconductor Processing Laboratory, Building 225, Room A111. They address safety issues involving the physical layout, equipment, and hazardous materials of the USPL. These guidelines and procedures address accident prevention, emergencies, and damage control.

Information in this report does not override or set aside any procedures, policies, or purposes of the NBS safety regulations; nor does any information in this document reduce the responsibilities regarding safety borne by all NBS employees involved.

\section{RESPONS IBILITIES :}

Responsibility for overall operation of the USPL is shared by two persons: the USPL Manager and the USPL Deputy Manager for Operations.

The USPL Manager and Deputy Manager for Operations have the responsibility to assure that procedures in this manual are carried out. All USPL staff have the responsibility to establish and maintain a safe working environment. The USPL Manager is responsible for distribution of the current version of this document to persons who anticipate working in the USPL, for assuring that such persons are knowledgeable about its contents, and for ensuring that its content is used as the basis for one of the required quarterly safety awareness meetings each year.

LABORATORY FUNCTION:

The Ultraclean Semiconductor Processing Laboratory is designed to produce small quantities of specialized semiconductor test specimens, experimental samples, prototype devices, and processed materials under well-controlled conditions with complete documentation of the processing history of these products. They are used for research on materials and process characterization and the development and evaluation of standard reference materials, measurement methods, and test structures. The facility does not produce large scale integrated circuits or similar complex structures. 
The USPL also provides a laboratory environment for research on materials and processes that is appropriate for the semiconductor program.

\section{LABORATORY LAYOUT:}

The USPL comprises an area of approximately 3700 square feet. It is located on the north side of the A corridor on the first floor in Building 225, adjacent to the loading dock. Within the USPL are seven rooms: Gowning Room, Ma in Room, Photolithography Room, Packaging Room, Ion Implantation Room, Storage Room, and Furnace Room. The first three are "clean rooms"; air within these rooms, with the exception of air exhausted into the chemical exhaust system, is recirculated continuously through particulate

filter/blower units mounted in the ceiling and the walls. Because of the sealed construction and the high speed air circulation, toxic gases leaked into the air could spread very quickly throughout the USPL.

A layout diagram of the USPL is shown in figure 1. The only nonemergency access is through the main entrance, Room Alll. All other corridor and outside doors are locked to entry but unlocked for exit.

The floor in the Furnace Room, Main Room, and Gowning Room, and that region of the Photolithography Room within 5 feet of the Main Room, is supported on steel beams approximately $51 / 2$ feet above the concrete slab. The remainder of the Photolithography Room and the Storage Room lie on a concrete slab directly on the ground. The Packaging Room and Ion Implantation Room are located over basement rooms.

Air is supplied primarily by air conditioning unit 16 (ACU-16) adjacent to the USPL on the west side, Room A125. The air in the Ion Implantation Room, Storage Room, and a fraction of the air in the Furnace Room, is supplied by ACU-7 in the attic. There are air pressure differentials of about $0: 01$ inches of water between rooms and a large amount of air transfers through pressure regulating registers and doorways. All ceilings are suspended (except in the Furnace Room); in the clean rooms the spaces above the ceilings, below the supported floors, and in the service areas are maintained at a lower pressure than the rooms themselves.

The total flow of air supplied to the USPL space is about 16,000 cubic feet per minute (CFM). About 6,000 CFM is exhausted via the chemical exhaust system by attic fan E-26.

\section{EMERGENCY NOTIFICATION LIST:}

The current emergency locator list of "Critical Experiment Key Persons" is posted at the entryway to the USPL, Room A111, and at the emergency exit of the Ion Implantion Room, A105. Only one person need be reached; alternates are listed in order of priority.

The person reached by telephone and alerted to a possible hazardous situation is responsible for carrying out appropriate procedures, including, when required, the notification of others on the USPL staff. 
The NBS emergency locator list on file with the NBS Emergency Planning Officer (Chief, Facilities Services Division) is updated periodically to reflect changes in personnel or responsibilities. The procedure for updating the list is for the CEEE administration office to file an NBS-1200. The Deputy Manager for Operations is responsible for making certain the list is kept current and that the door signs are also up-to-date. 


\section{GENERAL SAFETY INFORMATION}

MAJOR PROCESSING EQUIPMENT:

Semiconductor processing equipment within the Ultraclean Semiconductor Processing Laboratory are listed in table 1. Many of these have high voltage, high temperature, toxic materials, or other potential hazards associated with them. The table identifies hazards in reference to the equipment. The numbers at left correspond to identifying numbers in figure 1.

\section{SAFETY EQUIPMENT:}

Figure 2 shows the locations of fire extinguishers, circuit breakers, eyewashes, showers, emergency exits, emergency lights, alarm bells, and telephones.

Fire Extinguishers - Fire extinguishers are halon. There are three extinguishers; one is located in the Gowning Room, one is in the Furnace Room, and one is in the Ion Implantation Room.

Heat and Smoke Detectors - Rate-of-rise heat detectors are located on and above the suspended ceilings. Smoke detectors are located under the raised floor. Heat and smoke detectors are connected to the NBS Emergency Control Center in the basement of Building 101.

EMERGENCY ALARMS :

Audible alarms include fire bells and klaxon horns. The fire bells (see figure 2) are connected to the Building 225 fire alarm system. Klaxon horns located in three separate places (see figure 2) sound whenever the pressure differential in the chemical exhaust ducts falls below a preset value. The klaxon horn in the Main Room responds to reduced pressure in the exhaust duct to the Furnace Room, the horn in the Photolithography Room signals reduced pressure in the ducts to the wet stations, and the horn in the hallway outside the Ion Implantation Room (A105) responds to reduced pressure in the exhaust duct from the ion implanter.

A visible alarm in the Main Room signals water on the subfloor under the main room. This alarm is connected to the NBS Emergency Control Center.

HAZARDOUS MATERIALS WITHIN THE LABORATORY:

Toxic, corrosive, and flammable gases and liquids are used and stored in the USPL.

Compressed gases are contained at high pressure in steel cylinders, and may also be present at low pressures in stainless steel tubing connected to equipment. Table 2 is a list of all compressed gases used in the IISPL. In addition to these gases, ultra high purity oxygen and nitrogen are present. in stainless steel tubing beneath the floor in the Main Room. Delivery pressure in the tubing is less than 90 psig. 
$\stackrel{\frac{1}{2}}{ \pm}$

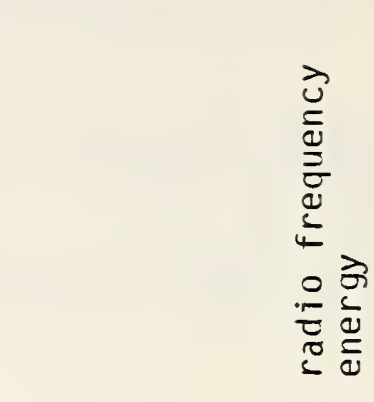

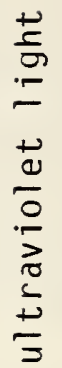

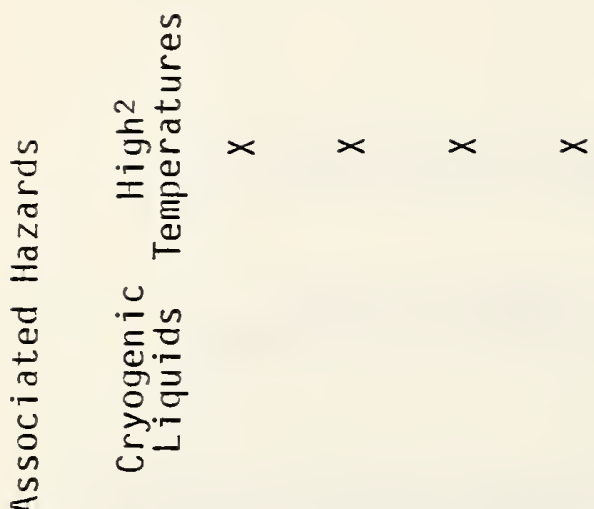

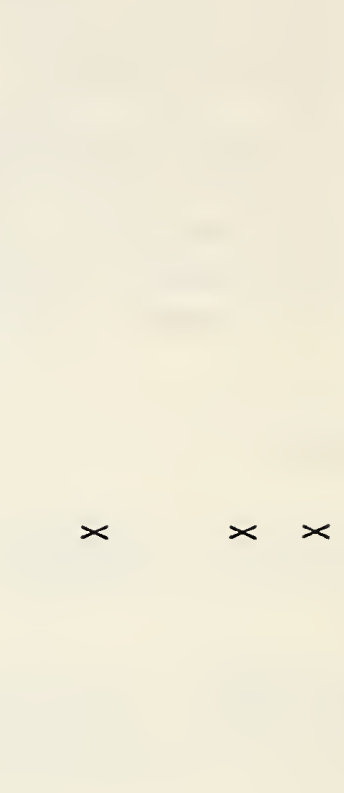

ए

$\rightarrow \quad \frac{2}{0} x$

$x \times x$

$\frac{2}{\pi}$

ㄴํㅇ

¿

든

产市

峞

जิ

T)

实

至宫

후을

出 4

it

年

政

$\circ$ 巳

$x \times x \times$

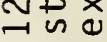

저-1

$4 \times$

วิ당

ए气

(1)

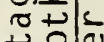

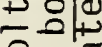

$=\frac{\pi}{3}$

टे

둥

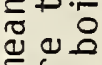

更

○芒

过范

은

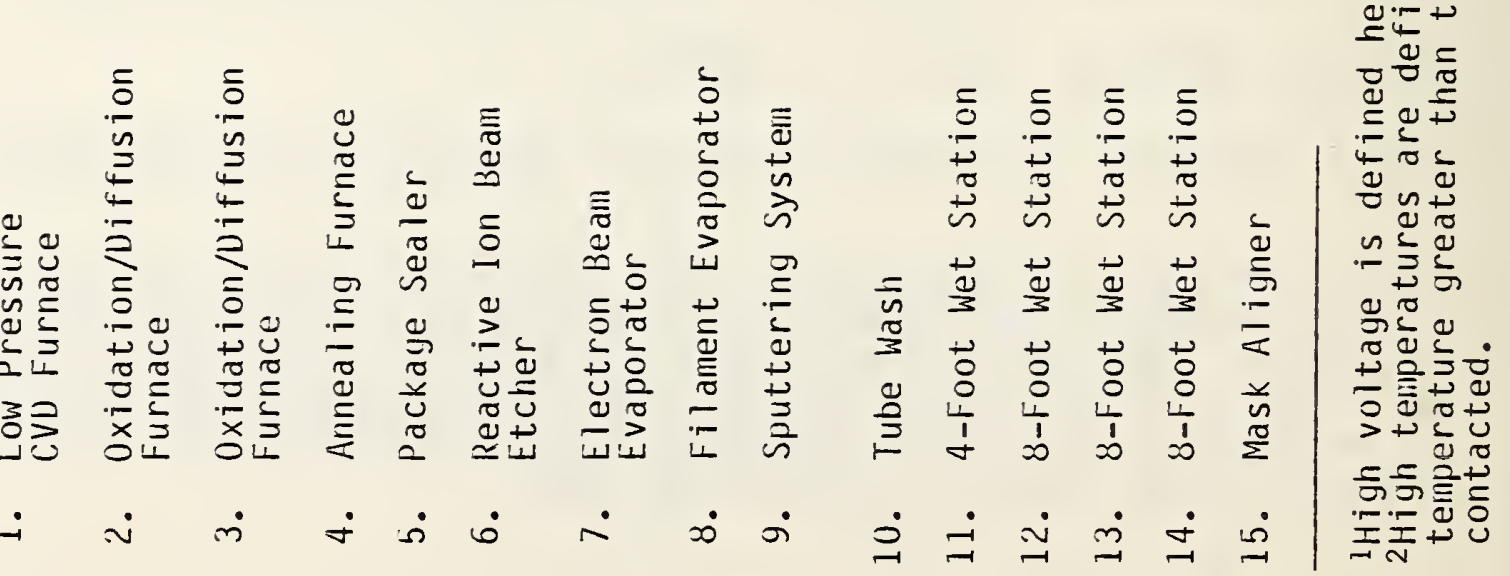

$\frac{0}{2}$ 


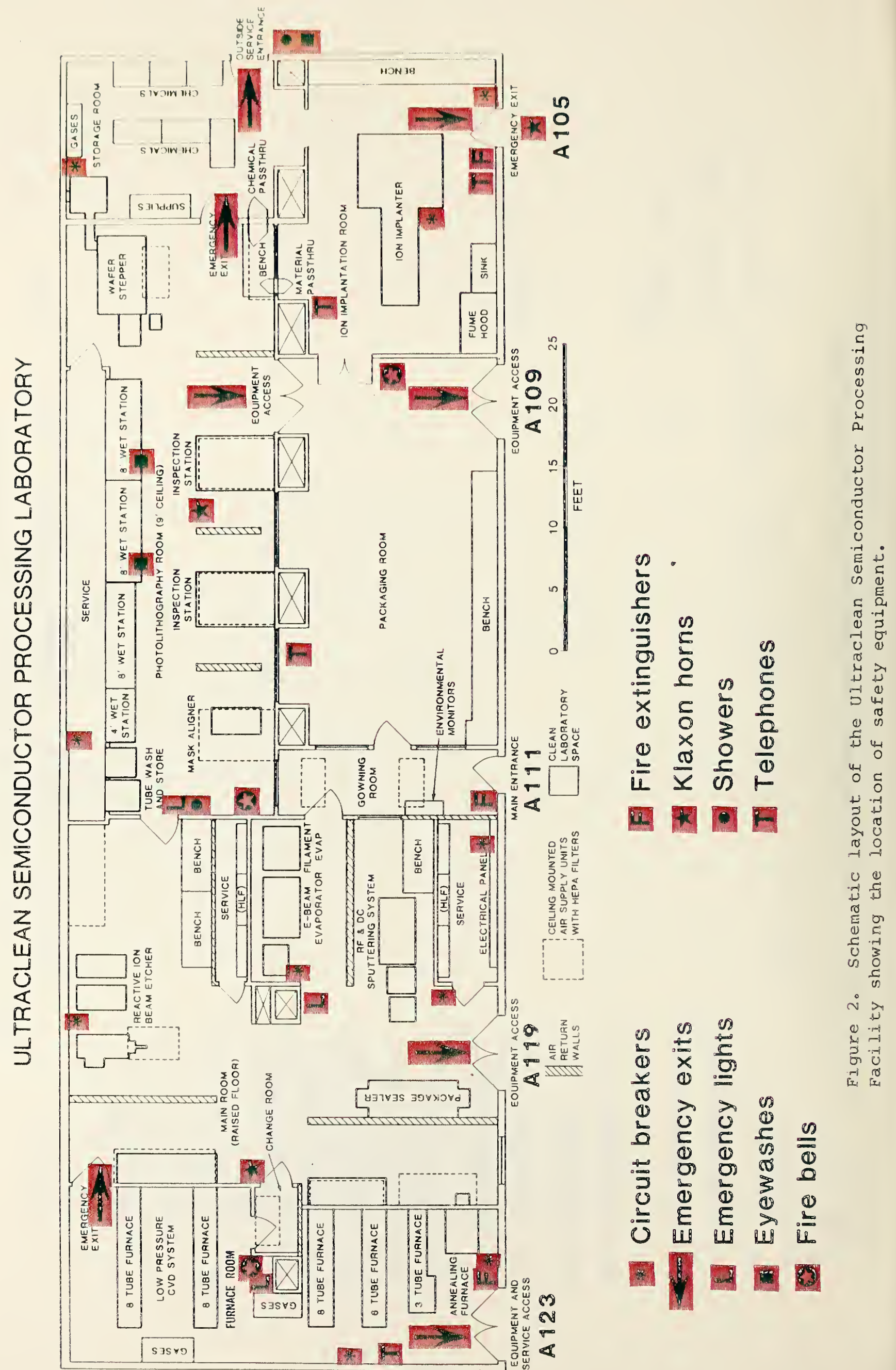


至安

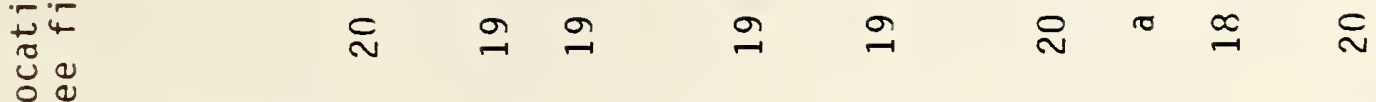

9.

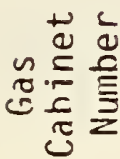

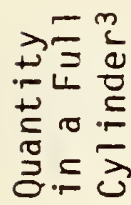

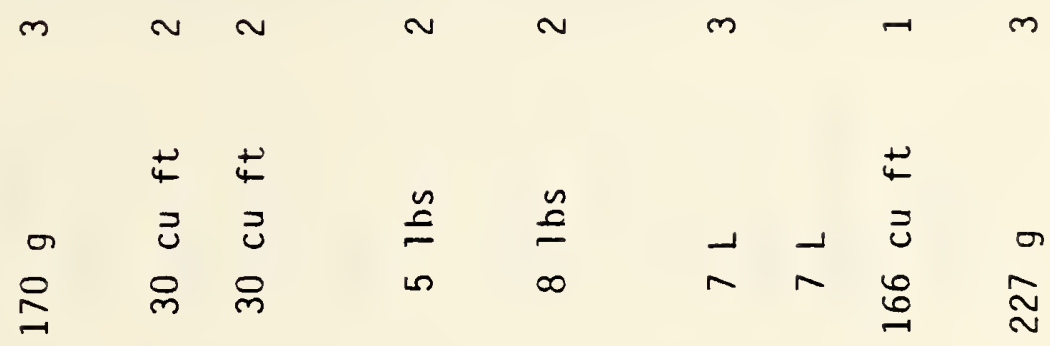

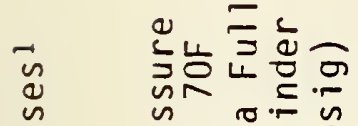

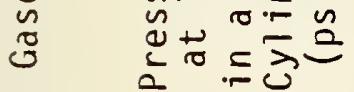

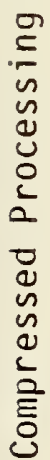

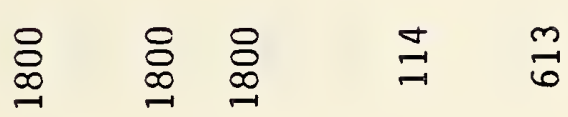

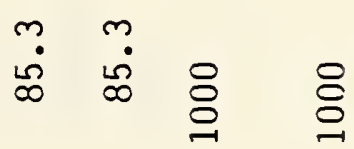

$\infty$

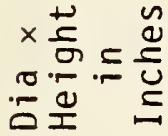

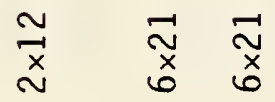

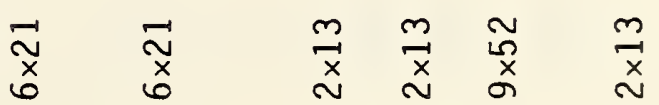

$\sum \stackrel{\sim}{N}$

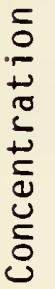

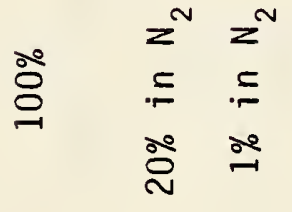

을

$n$

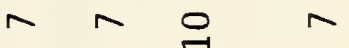

$\underset{\Xi}{\mathscr{\Xi}}$

ร

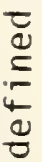

2

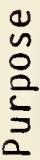

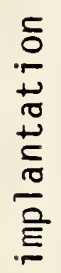

$\frac{0}{2}$

ᄋ̊ํ ஓீ<smiles>C1CCCCC1</smiles>

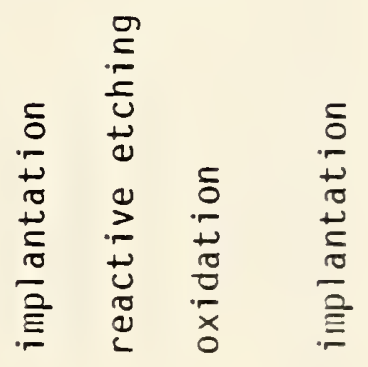

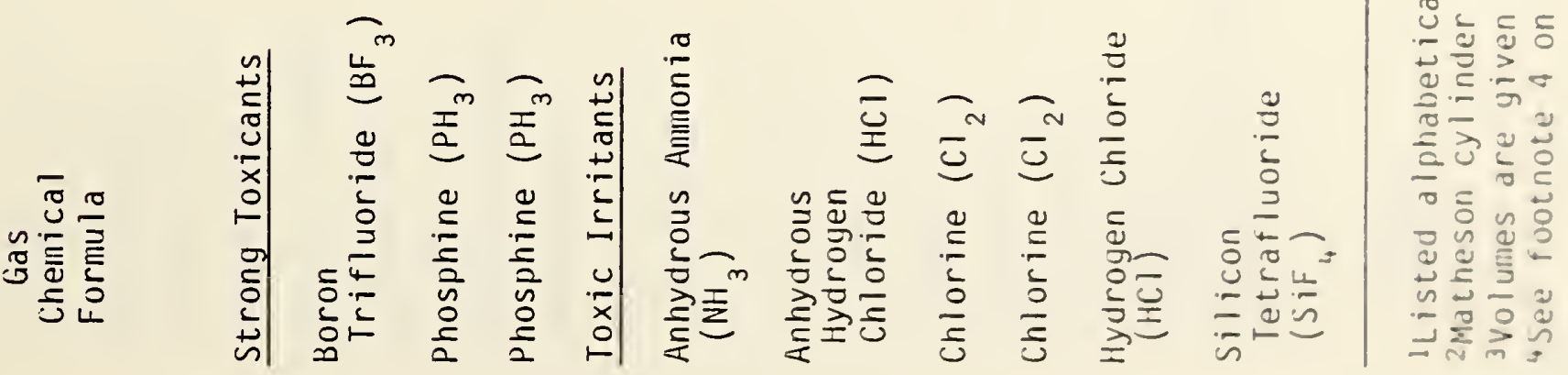


走市

$+$

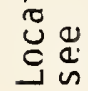

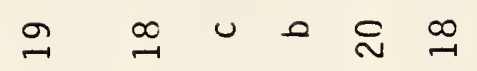

-

岂㐫

灾矿言

$m-1$

$m$

$m m$

$>=\frac{2}{2}$

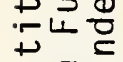

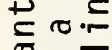

बิ

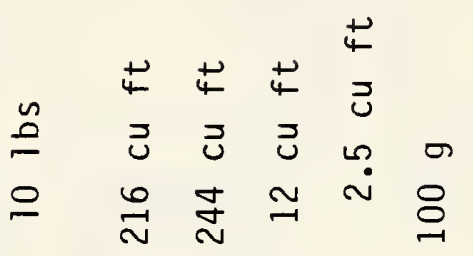

せせ罗廿せ

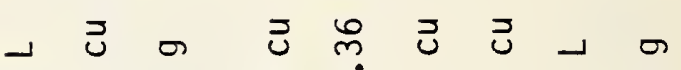

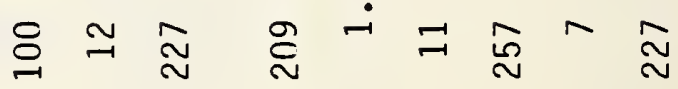

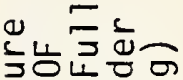

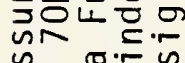

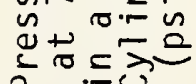

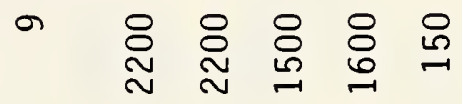

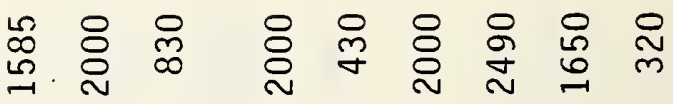

串

政

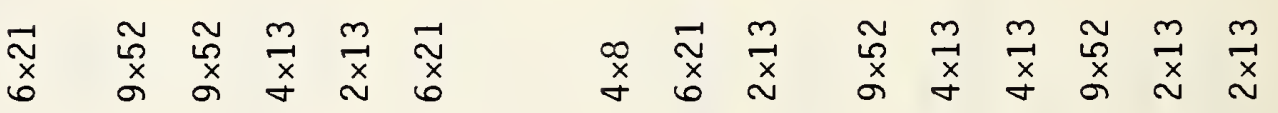

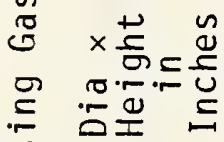

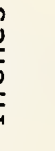

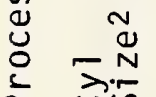

¿ उंs

mे $₫ \forall n m$

$6 m r$

登

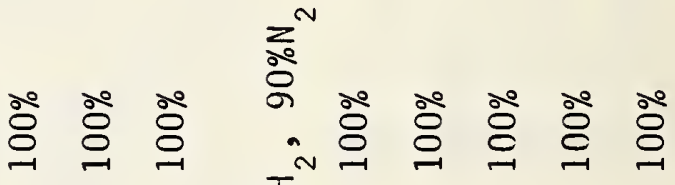

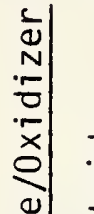

蒙

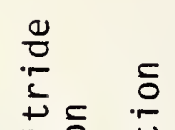

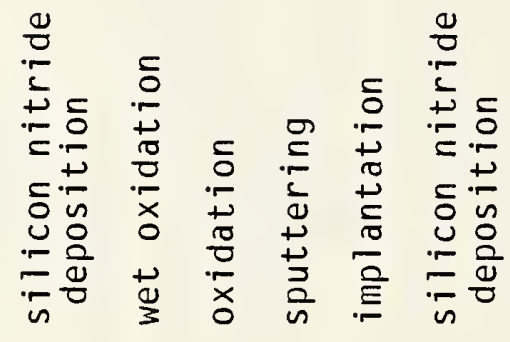

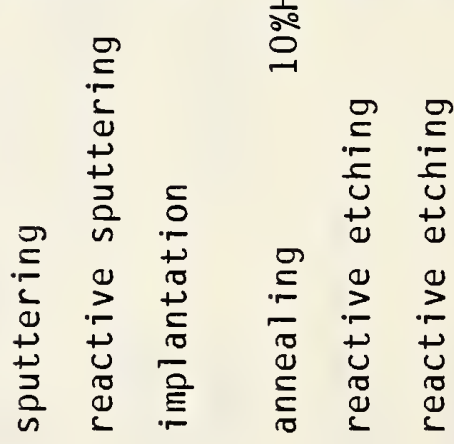

.

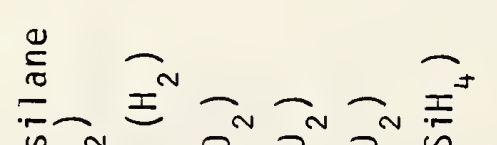

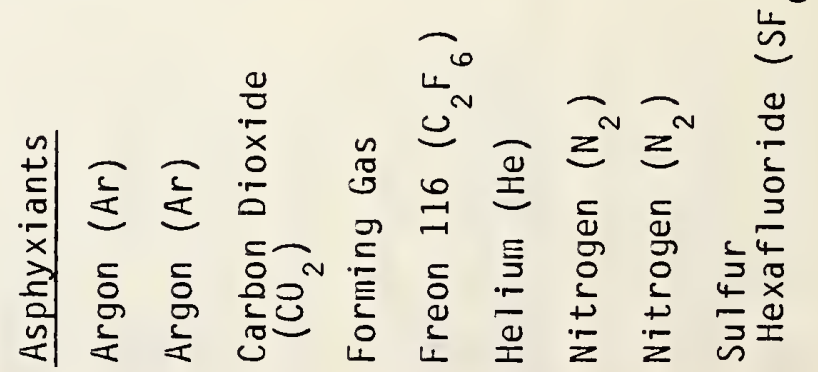

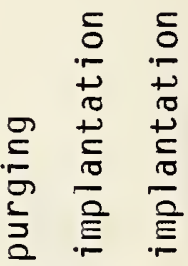

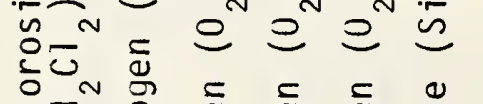

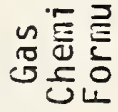

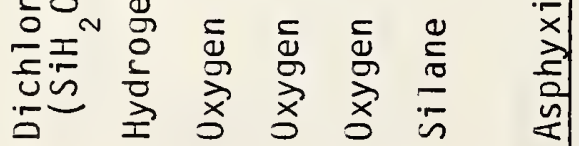


Corrosive liquids (acids and bases), solvents, and a variety of other organic chemicals are used in small quantities in the wet stations in the. Photolithography Room. Reserve amounts of these liquids are stored in continuously exhausted, fireproof cabinets in the Storage Room. A complete list of liquids (and some solids) used in the USPL is provided in table 3. Storage cabinet locations are shown in figure 2. Chemicals normally used in the Photolithography Room are also stored in cabinets under the wet stations. 


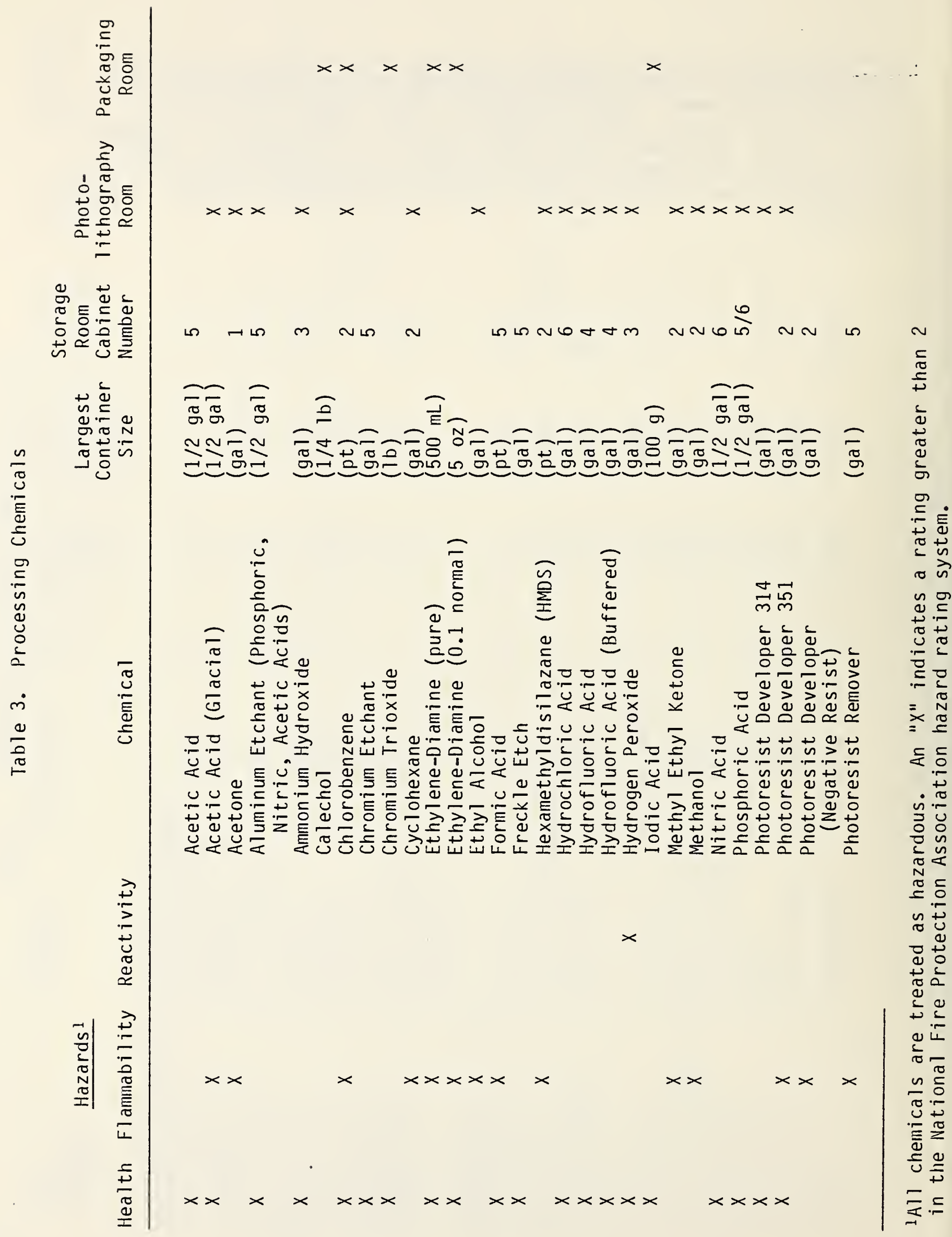




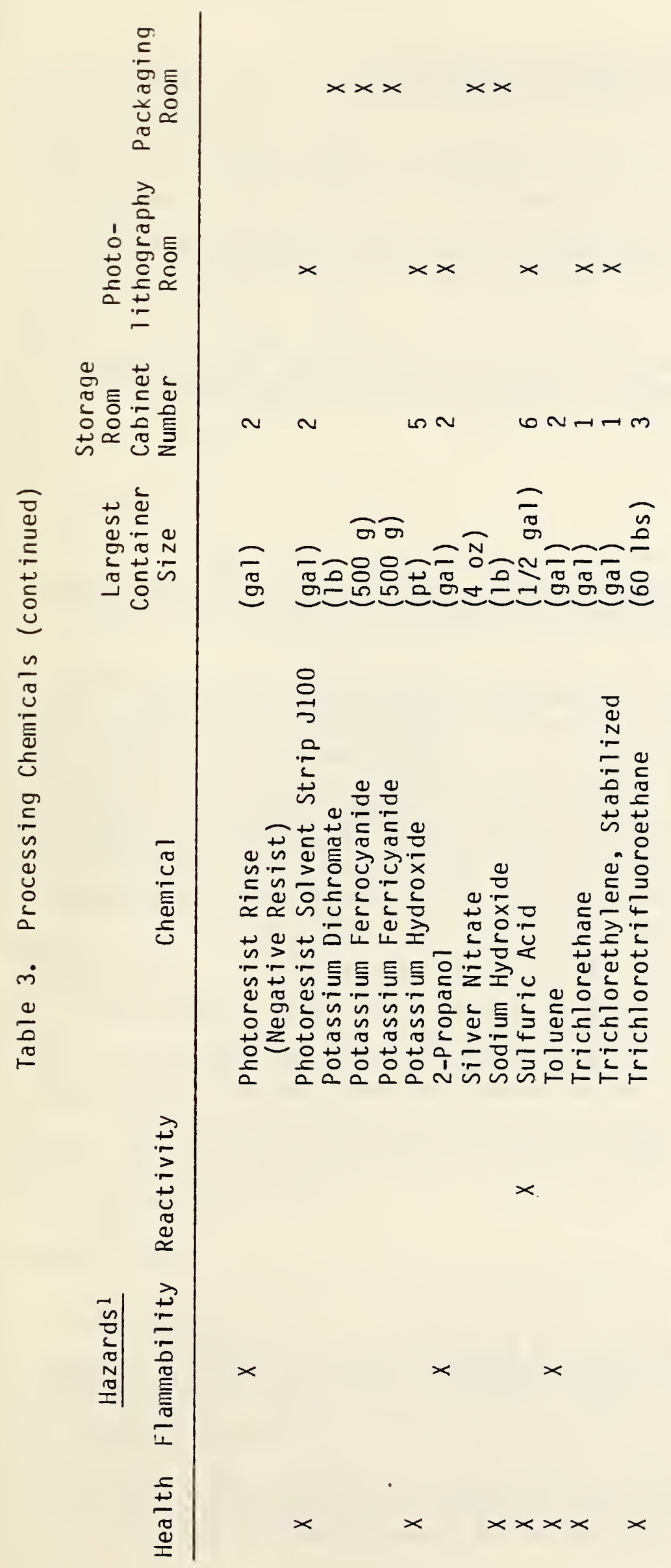


PURPOSE :

These standard operating procedures are intended to prevent injury to personnel and damage to property and to establish a uniform policy for the handling and control of toxic and hazardous materials and gases during use and storage in the Ultraclean Semiconductor Processing Laboratory.

SCOPE :

Standard Operating Procedures in this document apply only to the Ultraclean Semiconductor Processing Laboratory. They extend existing NBS safety procedures to the unique conditions in the USPL.

VISITORS:

Definition:

A "visitor" is a guest or new worker who has not yet become familiar with safety procedures and equipment and processes in the USPL.

Persons uninformed about the specific safety issues and procedures related to the USPL, and about the equipment and processes used in the USPL, are designated visitors. Therefore, all persons in their initial association with the USPL are visitors because they may be unprepared for the unique situations possible in the USPL. Guests and new workers who may have an indepth knowledge of semiconductor processes and processing equipment, clean rooms, etc., will appreciate the need to familiarize themselves with the specific conditions of the USPL. Such persons, recognizing the safetyrelated and cleanliness-related reasons for limiting their freedom-of-action in the USPL, will quickly acquire the necessary information to become "qualified workers" (as defined below).

Visitors to the USPL are not permitted inside the clean room, except with explicit clearance from the USPL Manager or the Deputy Manager for Operations. Permission to enter clean areas may be given only when the purpose of the visit cannot be accomplished without entry to the clean space. The person giving permission for visitors to enter clean areas must make proper arrangements to assure complete safety of everyone involved.

Visitors must be escorted at all times in clean rooms and in rooms in which hazardous materials are present.

Visitors who enter the clean room shall wear clean room garments, eye protection, and rubber gloves. They must also have on closed-top leather shoes. They cannot perform any processing activities, cannot handle hazardous materials, and cannot operate equipment. Hazardous activities must stop before a visitor comes near. Commercial equipment repair technicians are visitors, but they are permitted to operate the appropriate equipment.

The USPL Manager or Deputy Manager for Operations may relax certain restrictions for specific visitors, but only after they assure that the visitor has received a thorough explanation of permitted activities and 
safety procedures. The USPL Manager or Deputy Manager for Operations may determine also that certain visitors are qualified workers for certain specific activities. Such determination may be made only after assurance of competence in the specific activity and general knowledge of safety procedures.

It is the Deputy Manager for Operations' responsibility to notify USPL staff regarding changes in visitor or qualified worker status for any persons entering the clean areas. In the absence of such notification, each USPL member shall assume a person is a visitor and shall enforce all safety requirements, including the immediate cessation of hazardous procedures and the escorting of the person away from restricted areas.

QUALIFIED WORKERS:

\section{Definition:}

A "qualified worker" is a person who is aware of safety issues and procedures and has knowledge of the equipment and processes in the USPL. A qualified worker has a thorough knowledge of the contents of the current version of this manual, especially the Standard Operating Procedures.

Anyone performing any processing activities, handling hazardous materials, operating equipment, or even in close proximity to such activities within the USPL must be a qualified worker.

The Deputy Manager for Operations shall advise the USPL Manager when a visitor has adequate training, including specific knowledge of the unique conditions in the USPL, to be designated as qualified. The USPL Manager is then responsible for making final determination of status.

Persons may be designated qualified workers only for certain specified activities. All permanent processing staff are responsible for assuring that only qualified workers engage in activities in the USPL.

Qualified workers assigned to work in the USPL for extended periods shall hold current certification in CPR basic cardiac life support.

Qualified workers working with hazardous liquids shall not wear open shoes or shoes made from porous materials such as canvas. Also, such persons shall not wear contact lenses.

WORKING ALONE:

Definitions:

"Working alone" is the performance of work by an individual who is out of audio or visual contact with another individual.

"Audio contact" means a second person is in the same room.

"Visual contact" means two persons in the same room are able to see each other without changing locations or leaning over. 
A "confined space" is any space having limited means of access or egress and is so enclosed that adequate dilution ventilation is not obtained by natural (not forced) air movement. (See also NBS Safety Program Guide No. 9.)

When operations involving hazardous equipment or toxic materials are carried out, no fewer than two qualified workers must be in audio contact or visual contact inside the USPL. No one shall work alone when using hazardous equipment or toxic materials.

For activities involving equipment considered by the Deputy Manager for Operations to be not hazardous or activities not involving toxic materials, it is sufficient that at least one other person be aware of the presence of the qualified worker in the USPL. The second person, who must be qualified by the Deputy Manager for Operations to act if necessary, shall visually check on the well-being of the worker. That is, the second person shall come into visual contact at least once every 15 minutes.

The underfloor area in the main room is a designated confined space. When ventilation is off or reduced anywhere in the USPL, no one is allowed under the floor, except for Plant Division and Fire Protection Service personnel equipped to operate in such confined spaces.

When it is known that the underfloor ventilation is operating, work may be done under the floor. However, a person must remain at the floor opening and must verbally or visually check at least every five minutes on the well-being of anyone working under the floor.

\section{SCHEDULED UTILITY SHUTDOWNS:}

Scheduled shutdown of either ACU-16 or ACU-7 requires that exhaust fan E-26 be shut down also to prevent negative air pressures in the USPL with respect to the hallway. Processing Laboratory personnel shall assure that the chemical exhaust system alarms are disabled and that Plant personnel turn off E-26. No toxic gases or materials may be used when the air-handling and chemical exhaust systems are reduced or when the chemical exhaust alarms are disabled.

Therefore, prior to any scheduled reduction or shutdown of air handling or chemical exhaust systems, all work with toxic materials ceases, all hazardous materials are stored properly in closed containers, and all valves on gas cylinders are closed. After these preparations are completed, the chemical exhaust alarms are disabled. (Unless the stainless steel process gas lines are purged, small amounts of hazardous gases will be present in them, at pressures below 80 psig.)

Prior to scheduled air handling or exhaust system shutdowns, a clearly visible tag is attached to each wet station indicating a no-exhaust condition, under which no work with hazardous materials may occur. Also, all chemical and gas cabinets are tagged that exhaust is not operating and the cabinet may not be opened. The Deputy Manager for Operations is responsible for inspecting the USPL prior to scheduled utility shutdowns to verify that wet stations and gas and chemical cabinets are tagged appropriately. 
Scheduled shutdown of electricity, water, chilled water, compressed air, vacuum, nitrogen gas, or any other utility requires a notice be posted at the entryway so that affected equipment can be put into a safe standby state and relevant alarms disabled. The Deputy Manager for Operations maintains a current list of equipment affected by various utility outages.

\section{TOXIC AND HAZARDOUS COMPRESSED GASES:}

Policy - The concentrations and amounts of toxic gases are limited to minimum values determined to be necessary by the Deputy Manager for Operations.

\section{Definitions:}

The "Threshold Limit Value" (TLV) is the time-weighted average (TWA) concentration of substances to which people may be exposed for a standard work day (normally eight hours) and a standard work week (normally forty hours) as set by the American Conference of Governmental Industrial Hygienists and OSHA.

"Toxic and hazardous gases" means the gas phase of any substance which is detrimental to the health of living beings or which may cause danger because of its flammability, reactivity, or instability, or its ability to replace oxygen in an enclosed space.

Toxic and hazardous compressed gases are grouped into four categories corresponding to the predominant hazard represented by the gas:

Strong toxicants are highly toxic gases that are nonirritating, allowing exposure to lethal concentrations without warning. Some gases in this category are arsine, phosphine, diborane, hydrogen selenide, and carbon monoxide.

Irritants are highly toxic gases with adequate warning properties that normally cause voluntary withdrawal before lethal concentrations are reached. Some of the gases in this category are hydrogen chloride, chlorine, and ammonia.

Spontaneous flammables, ignitables, and oxidizers are gases whose principal hazard is flammability or the ability to support combustion. Some of the gases in this category are silane, oxygen, and hydrogen.

Asphyxiants are gases that require normal precautions in handling and storage. They can become dangerous if they are allowed to replace most of the air in a confined space. Some of the gases in this category are argon, nitrogen, carbon dioxide, and helium.

Strong toxicants are injurious to the internal organs and nervous system and even in small amounts can cause death. They enter the tissues of the hody during respiration. TLVs may be in the parts per million range. Irritants irritate the skin, mucous lining of the eyes, nose, throat, and respiratory system. Irritants may cause breathing difficulty, and even death. Asphyxiants are inert gases that can mix with air and lower the oxygen concentration. Although this is not an instantaneous process, asphyxiants 
can cause instaneous effects. Even though people may be able to "hold their breath" for about a minute, if their lungs are filled in just one inhalation with an inert gas, the person may suddenly faint or suffer respiratory arrest. When a person holds his breath, his lungs are filled with air containing oxygen which is utilized gradually. However, if a person's lungs do not contain any oxygen, they have no reserve at all and may suffer immediate effects. In an open, ventilated space, asphyxiants ordinarily present Tittle or no hazard.

Gas Use Procedures - The first time the use of a gas not previously used is planned, it is mandatory that certain arrangements be made. These arrangements are:

A. The Deputy Manager for Operations establishes a procedure, if none exists, for the physical handling of the toxic or hazardous gas.

B. The Deputy Manager for Operations approves the design of the process in which the gas is to be used, the design of all storage facilities, and the selection of monitoring equipment.

C. The Deputy Manager for Operations arranges for documenting the necessary maintenance procedures, the physical facilities, the handling and safety procedures, and the required monitoring equipment.

Periodic leak checks should be made on all gas lines using a helium leak detector. Leak tests are always made before operations with toxic and hazardous gases are begun.

Monitoring - A toxic gas monitoring system shall be used in conjunction with all processes utilizing gases categorized as strong toxicants. Sensors shall monitor gas cabinets, process equipment, and any vacuum pumps exhausting the gas. The TLV for boron trifluoride $\left(B_{3}\right)$ is 1 ppm (ceiling level); the TLV for phosphine $\left(\mathrm{PH}_{3}\right)$ is $0.3 \mathrm{ppm}$.

Each monitoring device must be capable of monitoring below and alarming at or below the TLV.

Piping - Piping is of rigid metal materials suited to the gas being piped and to expected pressures. All piping materials and accessories meet accepted engineering standards for structural strength, pressure ratings, and environmental requirements. Only safety-approved mechanical connectors or welded joints are used. All systems have an absolute minimum of joints. Piping run outside of an exhausted enclosure is solid, with a minimum number of fittings. Systems are tested according to acceptable techniques, such as helium leak testing.

Handling of Cylinders - Cylinders of gases categorized as strong toxicants, irritants, and spontaneous flammables, ignitables, and oxidizers shall be handled and installed only by the Deputy Manager for Operations or a designated qualified worker. A second person shall be in visual and audio contact at all times during changing and installation of cylinders. 
An inert gas purge system shall be provided to purge regulators during cylinder changing. An independent source of inert gas is required. The source for vacuum shall be different from the building vacuum system. The exhaust is piped to the chemical exhaust system, except for spontaneous flammables which are piped to a metal box outside the building.

Labeling and Documentation - All compressed gas cylinders shall have clearly visible and readable labets identifying their contents. All compressed gas cylinders shall be treated as though they were full, even when they are marked empty.

All piping shall be labeled to identify the piped gas.

All chemical and gas storage cabinets shall have a list of their contents on the outside of the cabinet. External warning labels shall be affixed to identify cabinets containing toxic gases, as: "CAUTION - PHOSPHINE." When hazardous gases are in use, a labeled lamp shall be lighted at the gas cabinet and on display panels visible throughout the USPL.

A current list of quantities and locations of all compressed gases on hand shall be kept by the Deputy Manager for Operations. This list is, in effect, an up-to-date version of table 2 .

Gas Cabinets - Ventilated toxic gas cabinets shall be provided for all supplies of toxic gases. Cylinders of strong toxicants, irritants, and spontaneous flammables, ignitables, and oxidizers must be used and stored only in appropriate gas cabinets. Cabinet construction shall be doublewalled of noncombustible materials. Cylinder straps or chains shall restrain gas cylinders. Each cylinder or manifold shall be pressure regulated within the cabinet.

Gas cabinets shall not be located adjacent to exits. Sufficient space shall be maintained to facilitate cylinder exchange.

Purge procedure instructions including identification of valves shall be posted in the cabinets. All cylinders shall be labeled as to contents and empty cylinders shall be marked as "EMPTY."

EVACUATION DRILLS:

A USPL evacuation drill shall be held a minimum of once per year with the cooperation of the NBS Fire Protection Services. This drill should be unannounced.

ALARMS :

All alarms within the facility shall be tested at least once per quarter. Any alarms found to be defective shall be repaired immediately and all affected hazardous work suspended until repairs are completed. The Deputy Manager for Operations is responsible for conducting tests, arranging repairs, and keeping a log documenting these activities. 
PURPOSE :

The purpose of Emergency Operating Procedures, once an emergency exists or is thought to exist, is 1) to provide guidelines to prevent or minimize injury to personnel and damage to property and 2) to allow identification of the seriousness of the emergency so that the necessary action can be taken with a minimum of confusion and damage or loss.

SCOPE :

Emergency Operating Procedures in this manual apply only to the Ultraclean Semiconductor Processing Laboratory. They extend existing NBS safety procedures to the unique conditions in the USPL.

Definition:

An "emergency" is defined as any unforeseen hazardous situation that could result in injury or death, or damage to property.

A broad range of situations can be emergencies. An emergency could be a small contained fire, chemical spili, or power failure providing a limited risk to personnel and property. However, it could be also an extremely serious situation, such as the release of toxic materials or a major fire.

An emergency requires the response of everyone in the USPL. It may involve also the groups named in Appendix I and may require the service of city, state, and other Federal agencies.

EVACUATION :

Definition:

"Evacuation" is the quick exiting of the USPL by all persons. NBS emergency services are immediately notified by calling x2222. Assembly is in the corridor outside the USPL, unless NBS emergency services decide to evacuate the entire building. In that case, assembly is in the Ruilding 225 parking area.

Determination to Evacuate - Each person in the Processing Laboratory has the responsibility to determine that an emergency exists or may exist and to raise the call to evacuate. The sole criterion is that the person perceives a situation that is or may be an emergency.

Evacuation shall be called in the event that any person becomes aware of:

1. An emergency anywhere within the USPL complex.

2. Evidence of a possible emergency, such as an odor or smoke within the USPL.

3. The sounding of the Building 225 emergency signals (fire bells or klaxon horns). 
In all emergency situations, having known or unknown causes, where the extent of the possible danger presents a threat of injury or damage, or where the extent of the possible danger is unknown, or where there is doubt as to the degree or immediacy of the emergency, personnel in the USPL shall evacuate.

In the case of the sounding of the Building 225 emergency signals, there may be no need to call x2222.

An atypical situation involving toxic or hazardous materials which is known to present no threat to humans or equipment may be handled by the Deputy Manager for Operations without immediately notifying NBS emergency services. Such situations and their resolution must be reported to the Division Management and to either the NBS Safety Office or Fire Protection Services, as appropriate. If there is any doubt about whether a threat exists or about the possibility of the escape of hazardous materials, NBS emergency services are called immediately.

Evacuation Procedures - Evacuation means:

- simultaneously leaving the USPL and spreading the alarm to evacuate,

- calling NBS emergency services (x2222), and

- assembly in the corridor outside the USPL.

Evacuation is by way of the nearest USPL door that can be safely approached and exited. During their transit to the exits, all personnel spread the evacuation alert to others in the USPL, if at all possible.

The Deputy Manager for Operations gathers information at the assembly site in the corridor and determines the next step.

In the case when NBS emergency services personnel have decided to evacuate the entire building, USPL personnel proceed by the nearest safe building exit to the Building 225 parking lot. USPL personnel assemble at a point on the grassy strip between the roadway and parking lot directly opposite the entrance to Building 225. They immediately verify the safe evacuation of all USPL personnel and await NBS emergency services. The Deputy Manager for Operations, or in his absence a processing technician familiar with the situation and the equipment and chemicals in the laboratory, makes his presence known to the NBS emergency services personnel.

Use of Judgment and Evacuation Guidelines - As in all human experience, each person in the USPL exercises judgment in the determination of the immediacy and extent of the problem, whether it is under complete control, and whether it is an emergency.

However, in emergency situations judgment may not be reliable, or there may not be time for discussion and decision-making. The guidelines in this section of the manual provide criteria for emergency action and therefore must be familiar to all appropriate personnel. If an emergency were to occur, USPL personnel then can respond effectively and efficiently without the need to spend time evaluating options or allowing time to elapse while trying to determine what to do. 
The evacuation guidelines are:

o when in doubt, get out,

- call x2222, and

- then evaluate the situation.

RESPONDING TO ALARM SIGNALS:

Building Alarms (fire bells and klaxon horns) - The response to building alarms is evacuation. When there is no evidence of the emergency existing in the USPL, such as smoke of flames, no more than 15 seconds shall be taken to secure or properly dispose of hazardous materials prior to evacuation.

When the alarms sound and a quick appraisal reveals any evidence of an emergency, such as an odor, smoke, or flames, evacuation is immediate.

Chemical Exhaust Alarms - When the klaxon horns inside the facility sound, all work with hazardous materials stops immediately and personnel evacuate.

Hazardous materials in wet stations may be secured or properly disposed of, if this can be done safely and within 15 seconds. Otherwise, personnel evacuate immediately.

Valves on hazardous gas cylinders are closed immediately, if this action can be completed safely and within 15 seconds, prior to evacuation. Similarly, equipment containing hazardous gases is put in the safest possible condition.

At the assembly point in the hallway the Deputy Manager for Operations, in cooperation with NBS emergency services personnel, determines when the laboratory may be reentered and what further action is required to assure safety.

PERSON LYING ON FLOOR:

When a person is discovered down on the floor, NBS emergency services are called. Unless it is known with certainty that no toxic materials are involved, no entry is made into the USPL. Personnel already within the same room at the time another person is discovered on the floor leave that room immediately, unless they know with certainty that no toxic materials are involved.

When it is known with certainty that no toxic materials are involved, and when immediate first aid must be given, and when only one other person is present, then summoning of NBS emergency services can be delayed only as long as absolutely necessary so that first aid can be given.

\section{POWER FAILURE}

In the event of an electrical power outage, all processing stops and hazardous gas cylinders are turned off and manual processing valves are turned off. Hazardous materials such as acids in wet stations are not secured, except when the Deputy Manager for Operations determines there is a greater hazard if they are not covered or disposed of, and even then only 
when emergency lighting allows adequate visibility. Certain equipment, identified by the Deputy Manager for Operations, is turned off or put in "standby." All personnel then leave the USPL. There is no immediate need to call NBS emergency services unless a known emergency exists or will exist if power is not restored quickly. 


\section{APPENDIX I \\ TELEPHONE EXTENSIONS FOR NBS HEALTH AND EMERGENCY SERVICES}

Health and Emergency Services

NBS Extension

NBS Emergency Hotline (Emergency Only)

Fire Protection Services

2584

Guard Office

2575

Health Unit

Safety Office

3366

Service Desk, Plant Division

2301 
APPENDIX II

NBS REFERENCES

Facilities Self-Protection Plan Gaithersburg Site, Facilities Services Division (November 1981).

NBS Administrative Manual: Chapter 12 - Safety

NBS Policy Bulletin No. 9: Occupational Safety and Health Program

NBS Safety Program Guides:

Number Subject

1

2

Installation and Use of Employee-Owned Electrical Appliances

Chemical Hoods

Liquid Hydrogen Operations

Hearing Conservation

Compressed Gas Cylinders

Recognition and Safe Handling of Peroxidizable Compounds

Compliance With Occupational Safety and Health Standards

Relative Hazards of Common Organic Solvents

Work in Confined Areas

10 Carcinogens

11 Eye Protection Program

12 Foot Protection

13 Laser Safety

14 Laboratory Vacuum Systems

15 Chemical Container Labeling

16 Hazardous Chemical Waste Diposal

17 Respiratory Protection

18 Working With Asbestos 
. . . . 
NBS-114A IREV. $2.8 C$ )

U.S. OEPT. OF COMM.

BIBLIOGRAPHIC DATA

SHEET (See in struction s)

1. PUBLICATION OR REPORT NO.

NBSIR $85-3149(R)$
2. Performing Organ. Report Nof 3. Publication Date

May 1985

4. TITLE AND SUBTITLE

Ultraclean Semiconductor Processing Laboratory Safe Operating Procedures Manual

5. AUTHOR(S)

G. P. Carver

6. PERFORMING ORGANIZATION (If joint or other than NBS. see instructions)

7. Contract/Grant No.

NATIONAL BUREAU OF STANDARDS

DEPARTMENT OF COMMERCE

WASHINGTON, D.C. 20234

8. Type of Report \& Period Covered

9. SPONSORING ORGANIZATION NAME AND COMPLETE ADDRESS (STreet, City. STOLE, ZIP)

National Bureau of Standards

Department of Commerce

Gaithersburg, MD 20899

10. SUPPLEMENTARY NOTES

[ Document describes a computer program; SF-185, FIPS Software Summary, is actached.

11. ABSTRACT (A 200-word or less factual summary of most significant informotion. If document includes a significane bibliogrophy or literature survey, mention it here)

Safe operating procedures and emergency procedures, designed to prevent accidents, to protect personnel and to control damage, were developed for the unique environmental conditions in the NBS Ultraclean Semiconductor Processing Laboratory (USPL). This manual containing descriptions of these safety guidelines, procedures for handing hazardous materials, and general laboratory information, such as safety equipment and the laboratory processing equipment and layout, is intended for persons who work in the USPL, but is also useful to safety, health, and fire protection personnel.

12. KEY WORDS (Six to twelve entries: alphabetical order: capitalize only proper names; and separate key words by semicalons) emergency procedures; processing laboratory; safe operating procedures; safety; safety manual

13. AVAILABILITY

Unlimited

X] For Official Distribution. Do Not Release to NTIS

[ Order From Superintendent of Documents, U.S. Government Printing Office, Washington, O.C. 20402.

Order From National Technical Information Service (NTIS), Springfield, VA. 2216I
14. NO. OF

PRINTED PAGES 

